\title{
BMJ Open Development of standardised programme content for phase II cardiac rehabilitation programmes in Australia using a modified Delphi process
}

\author{
Susie Cartledge (D) , ${ }^{1}$ Emma Thomas, ${ }^{1,2}$ Kerry Hollier, ${ }^{3}$ R Maddison ${ }^{1}$
}

To cite: Cartledge S, Thomas E, Hollier K, et al. Development of standardised programme content for phase II cardiac rehabilitation programmes in Australia using a modified Delphi process. BMJ Open 2019;9:e032279. doi:10.1136/ bmjopen-2019-032279

\section{- Prepublication history and} additional material for this paper are available online. To view these files, please visit the journal online (http://dx.doi. org/10.1136/bmjopen-2019032279).

$\mathrm{SC}$ and ET are joint first authors.

Received 11 June 2019 Revised 16 0ctober 2019 Accepted 06 November 2019

A) Check for updates

(C) Author(s) (or their employer(s)) 2019. Re-use permitted under CC BY-NC. No commercial re-use. See rights and permissions. Published by BMJ.

${ }^{1}$ Institute for Physical Activity and Nutrition, Deakin University, Geelong, Victoria, Australia ${ }^{2}$ University of Melbourne, Melbourne, Victoria, Australia ${ }^{3}$ National Heart Foundation of Australia, Melbourne, Victoria, Australia

Correspondence to

Dr Susie Cartledge;

susie.cartledge@deakin.edu.au

\section{ABSTRACT}

Objective To develop standardised programme content for Australian phase II cardiac rehabilitation (CR) programme.

Design Using the RAND/UCLA appropriateness method (RAM), a two-phase process including a comprehensive literature review and a two round modified Delphi process was undertaken to develop and validate content of a standardised CR programmes.

Participants An invited multidisciplinary expert advisory group (EAG; $n=16$ ), including CR health professionals (nurses, allied health professionals, cardiologist), academics, policy makers, representation from the Australian Cardiovascular Health and Rehabilitation Association and consumers, provided oversight of the literature review and assisted with development of best practice statements. Twelve members of the EAG went onto participate in the modified Delphi process rating the necessity of statements in two rounds on a scale of 1 (not necessary) to 9 (essential).

Main outcome measure Best practice statements that achieved a median score of $\geq 8$ on a nine-point scale were categorised as 'essential'; statements that achieved a median score of $\geq 6$ were categorised as 'desirable' and statements with a median score of $<6$ were omitted. Results 49 best practice statements were developed from the literature across ten areas of care within four module domains (CR foundations, developing heart health knowledge, psychosocial health and life beyond CR). At the end of a two-round validation process a total of 47 best practice statements were finalised; 29 statements were rated as essential, 18 as desirable and 2 statements were omitted.

Conclusions For the first time in Australia, an evidencebased and consensus-led standardised programme content for phase II CR has been developed that can be provided to CR coordinators.

\section{INTRODUCTION}

In Australia, almost 70000 people experience an acute coronary syndrome (ACS) event each year ${ }^{1}$ and approximately 20000 people die annually from coronary heart disease (CHD) ${ }^{2}$ making heart disease the single leading cause of death. Although mortality rates have declined in recent decades, ${ }^{3}$ the
Strengths and limitations of this study

- The two-round RAND/UCLA appropriateness method enabled in-depth discussion with the participants at the conclusion of each Delphi round which allowed participants a chance to hear other perspectives to take into consideration for the next rating round.

- A diverse group of participants were represented on the expert advisory group who undertook the modified Delphi process. This included cardiac rehabilitation clinicians, academics, policy makers, representation from the Australian Cardiovascular Health and Rehabilitation Association and a consumer.

- End users (cardiac rehabilitation clinicians) were given the opportunity to provide feedback on draft documents in relation to the content, how the final document would be produced (hard copy vs online) and where it could be accessed.

- The literature review was not systematic and therefore may not be exhaustive. However, the most recent and relevant international guidelines were reviewed in addition to high levels of evidence (where available) to formulate the best practice statements.

- While the best practice statements are derived from the international literature, they have been refined for the Australian healthcare context and may require some adaptation to be applicable to other settings.

prevalence of those living with CHD has increased. As modifiable risk factors account for approximately $80 \%$ of $\mathrm{CHD}^{4}$ and up to $50 \%$ of CHD admissions are repeat events, ${ }^{5}$ it is imperative that people with heart disease are educated in long-term self-management strategies to reduce the risk of further cardiac events, hospital readmissions and premature death. $^{5}$

Long-term self-management strategies are developed in cardiac rehabilitation (CR) programmes. These secondary prevention programmes are a multi-component intervention delivered by an interdisciplinary 
team that aim to halt the progression of disease and optimise functioning. This is achieved via exercise sessions and lifestyle change education that focus on regaining or maintaining physical capacity, well-being, medication compliance, and social and vocational participation. ${ }^{6-8}$ Research evidence demonstrates that exercise-based CR can significantly reduce the risk of cardiovascular mortality, ${ }^{7}$ improve health-related quality of life and decrease hospital admissions. ${ }^{9}$ However, the 'real-world' effectiveness of CR programmes is dependent on a range of factors including programme delivery, for example dose and content. Recent evidence demonstrates that 'comprehensive' CR programmes (eg, targeted six or more risk factors) have a larger effect on all-cause mortality than less comprehensive programme ${ }^{10} \mathrm{~s}$

In many countries (including Australia ${ }^{10}$ ) the expansion of CR programme has occurred organically, with programmes replicated from model sites but not standardised therefore national associations have since tried to implement quality standards retrospectively. Consequently, standardised CR programmes are limited, and when they do exist are largely implemented at the health organisation level rather than at the state or national level. Currently in Australia, considerable heterogeneity exists in the delivery of programmes nationally. This has been demonstrated in several national cross-sectional surveys investigating programme characteristics, ${ }^{11}$ screening practices for CVD risks and measurement tools used, ${ }^{12}$ and exercise training characteristics. ${ }^{13}$

In 2004, the National Heart Foundation of Australia and the Australian Cardiovascular Health and Rehabilitation Association (ACRA) developed a document titled a 'Framework for Cardiac Rehabilitation'. ${ }^{14}$ In 2012 the Heart Foundation released an expert guide to clinical practice for secondary prevention of CHD titled 'Reducing risk in heart disease'. ${ }^{15}$ These documents were further expanded on in 2014 by the ACRA and involved a set of core components consisting of five elements of cardiovascular disease secondary prevention and CR. ${ }^{6}$ The core components for quality delivery and outcomes of services include: (1) equity and access to services, (2) assessment and short-term monitoring, (3) recovery and longer-term maintenance, (4) lifestyle/behavioural modification and medication adherence and (5) evaluation and quality improvement. ${ }^{6}$ While the core components provide broad overarching guidance, clinicians are still required to interpret and implement these and define and deliver key features within their daily clinical practice. Identifying key features that should be included in all CR programmes has been called for in a prior National Secondary Prevention of Coronary Disease Summit in $2011 .^{16}$

Therefore the aim of this study was to develop standardised programme content for phase II CR programmes in Australia (referred hereafter as 'programme content') to be used by CR coordinators. Specific aims included ensuring programme content was evidenced based, standardised but with flexibility to provide individualised
Secondary Level Evidence Review

- International cardiac rehabilitation guidelines, core components - Overviews and systematic reviews

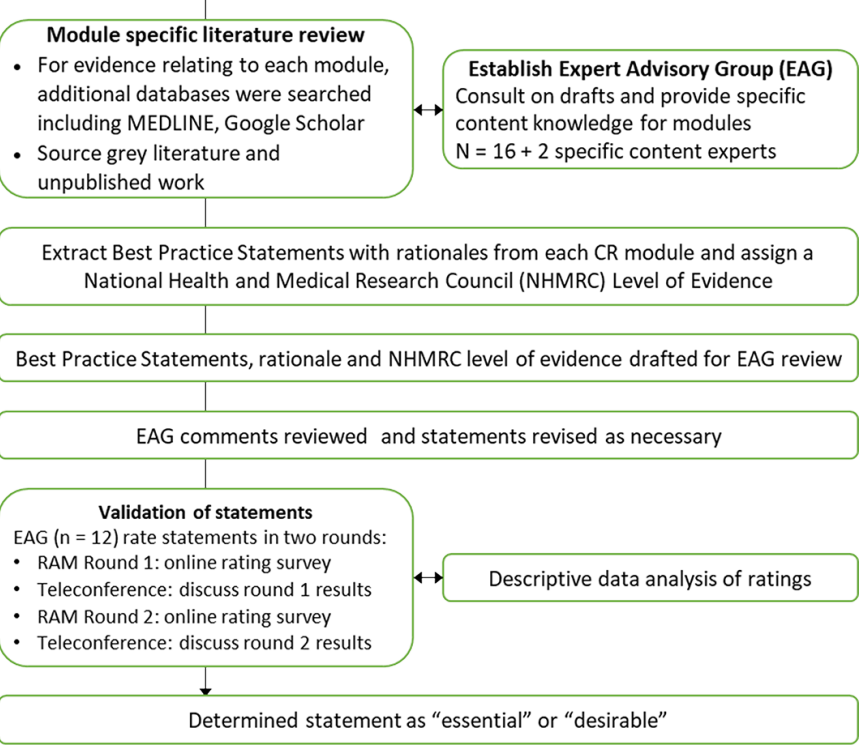

Figure 1 Overview of the RAND/UCLA appropriateness method adapted from Fitch et al. ${ }^{17}$

education for clients, culturally aware, person centred and built on the existing ACRA core components. ${ }^{6}$ Furthermore, we aimed for the standardised programme content to be applicable across a range of delivery modes (face-to-face, telehealth, web or mobile phone).

\section{METHODS}

This work was undertaken by the National Heart Foundation of Australia in partnership with researchers (Deakin University) and was funded by Safer Care Victoria.

\section{Design}

The RAND/UCLA appropriateness method $(\mathrm{RAM}){ }^{17}$ was used to guide the development of the programme outline (figure 1). The RAM method involves two main steps; (1) a comprehensive review and synthesis of the literature and (2) a two-round modified Delphi process.

\section{Literature review and synthesis of evidence}

In February 2018, a review of literature was undertaken in three phases. This was performed by two authors (SC, ET) and guided by the RAM manual. ${ }^{17}$ The first phase involved a review of national and international CR guidelines and core component documents, in addition to organisation and association websites known to provide these publications. CR, ACS guidelines and core components were included if they were from comparable highincome countries and regions to Australia (UK, USA, Canada, New Zealand, and Europe) and published in English. To ensure guidelines aligned with recent evidence, only documents published after the year 2000 were included. Guideline data were extracted using an online spreadsheet, which was accessible to all authors for review and discussion. Synthesis of these data informed 
the basis for identifying core areas for the CR programme content.

Given there have been a number of systematic reviews of the effectiveness of CR, and following the RAM manual, the second phase of the literature review involved searching the Cochrane Library (2000-2018) for overviews and systematic reviews of identified CR programme content (eg, exercise training, nutrition education, smoking cessation). Where no Cochrane systematic reviews were available for content areas, the third phase of the literature review was undertaken. Search terms (online supplementary table 1) were developed for each content area and applied to the following databases: PubMed, TRIP database (www.tripdatabase.com), MEDLINE and Google Scholar between 2000 and 2018. Study designs were limited to the highest level of evidence available (systematic reviews, followed by randomised controlled trials). In addition, we also searched reference lists of clinical practice guidelines and systematic reviews to identify other appropriate and high-quality evidence (figure 1).

\section{Participants-expert advisory group}

An expert advisory group (EAG) (table 1) was formed in February 2018 to provide input for this programme of work in addition to a working group. Membership of the EAG was guided by the Heart Foundation, in consultation with ACRA and the authors, and aligned with the RAM manual. EAG membership aims were to include both clinical and academic CR experts or leaders, multidisciplinary representation from the majority of Australian states and territories where possible, and to include consumers (previous CR participants). Potential members were then approached by Heart Foundation to gauge their interest and availability. Specific roles of the EAG included (1) assistance in identifying appropriate and relevant literature or documents in addition to the authors search, (2) guidance on the overall direction and format of the programme outline, (3) review of each developed module, providing feedback to the authors, (4) participation in a modified Delphi process to determine what content should be included in the CR programme outline. In addition to the working group, the EAG was comprised of 16 members and met five times via scheduled teleconferences with one face-to-face meeting. Members of the EAG had the option to contact the authors and the Heart Foundation project managers at any time with feedback.

All participants were required to provide informed consent prior to participation.

\section{Development of programme outline modules}

Following phase I of the literature review, best practice statements referring to what should be included in CR programmes from the identified clinical guidelines were extracted by authors (SC, ET) into an Excel spreadsheet. Extracted information was synthesised under content areas (eg, exercise training, nutrition, psychosocial health) and included: the guideline reference(s), an overall recommendation and rationale, National Health and Medical Research Council (NHMRC) level of evidence. ${ }^{18}$ Best practice statements were then devloped and formed the basis of each 'module'. The EAG then provided guidance on what additional information should be provided to enable implementation of the best practice statements across CR sites and included: a module aim, example content of how each recommendation could be implemented and resources (ie, action plans, websites, phone applications). Modules were then drafted (SC, ET, RM) with input from content experts (EAG or external if EAG members did not have specific skills, ie, smoking cessation, pharmacology). The additional content experts provided guidance on how the best practice statements could be implemented within a CR setting and the most appropriate resources available. For example, broad nutritional education best practice statements on making healthy dietary choices to reduce cardiovascular risk were expanded by providing the five principles of the Heart Foundations' Eating for Heart Health Position Statement, along with tips, resources and additional links (example module, online supplementary file 2 and full resource available via https://www.heartfoundation.org.au/for-professionals/clinical-information/cardiac-rehabilitation-for-health-professionals).

\section{Patient and public involvement}

We included a patient consumer with lived experience of a heart event and CR as part of the EAG. Once the modules were in full draft, they were also reviewed by a further two patient consumers (one female and one male). CR coordinator end users were also consulted through a public forum ( $\mathrm{n}=15,14$ September 2018) with members from the local Victorian state chapter of ACRA invited to review draft modules in a workshop format. Feedback from attendees was collated and then incorporated into the modules where appropriate. The modules were then finalised by the working group.

During resource development, ACRA members from other states were also consulted via various public presentations (Heart Foundation workshops in Melbourne (September 2018) and Canberra (July 2019)). The finalised resource was presented at the ACRA Annual Scientific Meeting (August 2019) and will also be disseminated through ACRA state chapters at future local state conferences. In addition all CR services will receive the finalised resource via the National Heart Foundation and ACRA mailing lists. A webinar will also be delivered to enhance reach to clinicians and provide an explanation of the resource.

\section{Validation of best practice statements}

We used the RAM modified Delphi method ${ }^{17}$ to validate the best practice statements and to determine which statements would be classified as essential to deliver within a programme versus desirable. The Delphi method involves a group of experts led by a facilitator, to determine the appropriateness of clinical procedures, or in this case, 
Table 1 Expert advisory group members including working group $(n=6)$ and Delphi participants $(n=12)$

\begin{tabular}{|c|c|c|c|c|}
\hline Member & $\begin{array}{l}\text { Organisation } \\
\text { (at time of project) }\end{array}$ & Professional role(s) & Expertise & State/country \\
\hline \multicolumn{5}{|l|}{ Working group } \\
\hline Dr Sue Forrest & $\begin{array}{l}\text { National Heart Foundation } \\
\text { of Australia }\end{array}$ & Managerial, policy & Chair & Victoria \\
\hline $\begin{array}{l}\text { Professor Ralph } \\
\text { Maddison }\end{array}$ & Deakin University & Research & $\begin{array}{l}\text { Academic Chair } \\
\text { Working group }\end{array}$ & Victoria \\
\hline $\begin{array}{l}\text { Dr Susie } \\
\text { Cartledge }\end{array}$ & Deakin University & Research & Working group & Victoria \\
\hline $\begin{array}{l}\text { Dr Emma } \\
\text { Thomas }\end{array}$ & $\begin{array}{l}\text { Deakin University and } \\
\text { University of Melbourne }\end{array}$ & Research & Working group & Victoria \\
\hline Kerry Hollier & $\begin{array}{l}\text { National Heart Foundation } \\
\text { of Australia }\end{array}$ & Policy & Working group & Victoria \\
\hline $\begin{array}{l}\text { Roni } \\
\text { Beauchamp }\end{array}$ & $\begin{array}{l}\text { National Heart Foundation } \\
\text { of Australia }\end{array}$ & Policy & Working group & Victoria \\
\hline \multicolumn{5}{|c|}{ Expert advisory group members who participated in RAND/UCLA modified Delphi } \\
\hline $\begin{array}{l}\text { A/Professor } \\
\text { Adrienne O'Neil }\end{array}$ & University of Melbourne & Research & Mental health & Victoria \\
\hline $\begin{array}{l}\text { A/Professor } \\
\text { Nicholas Cox }\end{array}$ & $\begin{array}{l}\text { Western Health and } \\
\text { University of Melbourne }\end{array}$ & Clinical, research & Cardiology & Victoria \\
\hline Emma Boston & $\begin{array}{l}\text { St John of God, Frankston } \\
\text { Rehabilitation Hospital }\end{array}$ & $\begin{array}{l}\text { Clinical, } \\
\text { ACRA Victoria President }\end{array}$ & Nursing & Victoria \\
\hline Kim Gray & Austin Health & $\begin{array}{l}\text { Clinical, Incoming } \\
\text { President-ACRA National }\end{array}$ & Physiotherapy & Victoria \\
\hline $\begin{array}{l}\text { Professor Robyn } \\
\text { Gallagher }\end{array}$ & University of Sydney & Research, ACRA National President & Nursing & $\begin{array}{l}\text { New South } \\
\text { Wales }\end{array}$ \\
\hline Cate Ferry & $\begin{array}{l}\text { National Heart Foundation } \\
\text { of Australia }\end{array}$ & $\begin{array}{l}\text { Managerial, National Heart Foundation of } \\
\text { Australia representative on ACRA }\end{array}$ & $\begin{array}{l}\text { Cardiovascular } \\
\text { health policy }\end{array}$ & $\begin{array}{l}\text { New South } \\
\text { Wales }\end{array}$ \\
\hline $\begin{array}{l}\text { Stephen } \\
\text { Woodruffe }\end{array}$ & $\begin{array}{l}\text { West Morton Hospital and } \\
\text { Health Service }\end{array}$ & Clinical & $\begin{array}{l}\text { Cardiac exercise } \\
\text { physiology }\end{array}$ & Queensland \\
\hline Beth Meertens & $\begin{array}{l}\text { National Heart Foundation } \\
\text { of Australia }\end{array}$ & Policy & Dietetics & Queensland \\
\hline Dr Bridget Abell & Bond University & Research & Exercise physiology & Queensland \\
\hline $\begin{array}{l}\text { Professor Robyn } \\
\text { Clark }\end{array}$ & Flinders University & Research & Nursing & South Australia \\
\hline $\begin{array}{l}\text { Professor Lis } \\
\text { Neubeck }\end{array}$ & $\begin{array}{l}\text { Edinburgh Napier } \\
\text { University }\end{array}$ & $\begin{array}{l}\text { Research, Immediate past national ACRA } \\
\text { president }\end{array}$ & Nursing & $\begin{array}{l}\text { United } \\
\text { Kingdom } \\
\text { (previously } \\
\text { New South } \\
\text { Wales) }\end{array}$ \\
\hline Cyril Hennequin & Not applicable & Consumer & Patient consumer & Victoria \\
\hline
\end{tabular}

ACRA, Australian Cardiovascular Health and Rehabilitation Association.

the appropriateness of content to be included in CR programmes. ${ }^{17}$

Following the RAM manual, ${ }^{17}$ the modified Delphi process consisted of two rating rounds. Prior to rating rounds, all members of the EAG were briefed on the procedure, provided with a timeline for the process and an opportunity to ask questions. Rating rounds were conducted via an online survey platform (Qualtrics, V.10$11 / 2018$ ) distributed via email. The online rating survey consisted of the plain language statement, followed by a tick box to indicate consent and release of participant name for publication purposes; the best practice statements; rationale with accompanying references and NHMRC level of evidence. While all best practice statements were deemed appropriate as they were derived from the comprehensive literature review, participants were asked to rate each best practice statement on a scale of necessity. The provided scale was from 1 to 9 , where 9 indicated that it would be improper clinical judgement not to provide the intervention and one indicated that 
although the intervention is appropriate, it was not necessary. As per the RAM manual, prior to rating each recommendation, the EAG participants were asked to consider a 'typical' CR site (ie, with average patients, clinicians and in a typical setting) and they were specifically requested not to consider cost implications when making their judgements.

Each round was followed with a teleconference with the EAG to discuss results, provide clarification if necessary and work towards consensus. In addition, once round 1 was complete, all participants were provided with an individualised scoring results sheet that indicated both their own scores and scores from all participants, for their review. At the conclusion of round 2, all participants were sent an overall scoring sheet with the calculated median for each best practice statement.

This modified Delphi method with group discussion has been demonstrated to achieve results that are valid ${ }^{19}$ and reliable. ${ }^{1720}$ In addition, we used an experienced facilitator during group discussions $(\mathrm{SF})$, which has been shown to control for bias, and a panel facilitator who was familiar with Delphi methodology (ET). ${ }^{17}$

\section{Analysis}

Rating scores were reviewed and descriptively summarised after each round according to RAM Delphi protocol. Initial analysis involved calculating the median score for each statement and assessing the dispersion of scores. There were no a priori cut-off scores to determine if best practice statements would be essential or desirablescoring cut-offs were determined once the data were reviewed and the dispersion of rating scores could be assessed.

\section{RESULTS}

\section{Literature review}

In total, eight clinical practice guidelines were identified that related to CR in six countries (Australia, ${ }^{21} \mathrm{New}$ Zealand ${ }^{22}$ the UK, ${ }^{23-25}$ the USA, ${ }^{26}$ the Netherlands ${ }^{27}$ and Canada $^{28}$ ), one region ${ }^{29}$ (Europe) and one international guideline (from the $\mathrm{WHO}^{30}$ ) (online supplementary table 2 ). The identified Australian guideline ${ }^{21}$ was related to the care of patients with ACS generally and provided only brief mention of CR. In addition, seven core component documents were identified $^{614152631-33}$ (online supplementary table 3 ).

Common areas of content identified from the guideline synthesis were: exercise training, smoking cessation, psychological and psychosocial interventions, risk factor education (physical activity, diet, weight control, blood pressure, medication adherence, cholesterol/lipids), disease management education (anatomy and physiology, chest pain management, cardiopulmonary resuscitation training) and vocational rehabilitation.

A search of the Cochrane Library identified one overview $^{9}$ and 11 reviews ${ }^{34-44}$ that were applicable to our criteria (online supplementary table 4 ). Where information for
Table 2 Structure of programme outline following literature review

\begin{tabular}{|c|c|c|}
\hline $\begin{array}{l}\text { Module } \\
\text { categories }\end{array}$ & Module title & $\begin{array}{l}\text { Number of } \\
\text { best practice } \\
\text { statements }\end{array}$ \\
\hline \multirow{2}{*}{$\begin{array}{l}\text { Cardiac } \\
\text { rehabilitation } \\
\text { foundations }\end{array}$} & $\begin{array}{l}\text { 1. Initial assessment and } \\
\text { goal setting }\end{array}$ & 13 \\
\hline & $\begin{array}{l}\text { 2. Heart education and } \\
\text { self-management }\end{array}$ & 2 \\
\hline \multirow{5}{*}{$\begin{array}{l}\text { Developing } \\
\text { heart health } \\
\text { knowledge }\end{array}$} & $\begin{array}{l}\text { 3. Medication education } \\
\text { and review }\end{array}$ & 3 \\
\hline & $\begin{array}{l}\text { 4. Managing medical risk } \\
\text { factors }\end{array}$ & 3 \\
\hline & $\begin{array}{l}\text { 5. Exercise training and } \\
\text { physical activity }\end{array}$ & 2 \\
\hline & $\begin{array}{l}\text { 6. Healthy eating and } \\
\text { weight management }\end{array}$ & 5 \\
\hline & $\begin{array}{l}\text { 7. Tobacco cessation and } \\
\text { alcohol reduction }\end{array}$ & 4 \\
\hline $\begin{array}{l}\text { Psychosocial } \\
\text { health }\end{array}$ & 8. Psychosocial well being & 9 \\
\hline \multirow{2}{*}{$\begin{array}{l}\text { Life beyond } \\
\text { cardiac } \\
\text { rehabilitation }\end{array}$} & 9. Activities of daily living & 5 \\
\hline & 10. Reassessment & 3 \\
\hline Total & & 49 \\
\hline
\end{tabular}

the module development could not be sourced from these reviews, a separate search was undertaken to find the highest level of evidence. The education categories identified in the guideline review provided the basis for formulating the final ten developed modules (table 2), which consists of a total of 49 best practice statements.

\section{RAM round 1}

In October 2018, 12 members $(75 \%)$ of the EAG participated in RAM round 1 of the Delphi process. The remaining four members of the EAG were not available at the time the Delphi process was conducted. Overall, the majority of statements rated very highly, with little dispersion. As a result, we used strict criteria to determine the definition of agreement (all responses falling between 7 and 9) and best practice statements that would be deemed essential (median $\geq 8$ ). These decisions were guided by the RAM Delphi protocol. ${ }^{17}$

The high level of agreement was the basis of our discussion in the scheduled teleconference following this rating round. In response to this, the EAG were asked to consider which best practice statements should be included as an essential component of CR programme versus statements which would be desirable for programmes (where there was capacity to deliver them). Inconsistent scoring within module categories (ie, one managing medical risk factor best practice statement scored highly, but the others did not) was also discussed. All discussion points during the teleconference were for EAG members to consider during the second rating round. 


\section{RAM round 2}

The same 12 EAG members participated in RAM round 2 of the Delphi process. Greater dispersion of scores was observed in round 2 compared with round 1; however, there was still clear consensus on which statements would be essential, desirable or inappropriate (table 3). Advance care planning as part of the initial assessment module scored $<6$ and therefore was deemed inappropriate and was omitted.

Discussion during the round 2 teleconference focused on best practice statements which had inconsistent scoring within module categories. During these discussions all participants in the teleconference had an opportunity to discuss scoring and content experts from within the EAG were also asked to comment. Based on discussions, four statements were increased to an essential ratingthis was a result of omitting a singular outlier score of below 7 (as outlined in the RAM guidelines ${ }^{17}$ ) and with consensus from the group (table 3). The other topic of discussion was ensuring this work was in line with other national work on quality indicators and minimum data sets. ${ }^{45-49}$ Our aim was to ensure the programme content was consistent with the indicators and minimum data set requirements. Again, we took the same approach for those statements of omitting a singular outlier score and ensuring group consensus.

At the completion of round 2, final scoring resulted in 28 essential best practice statements, 17 desirable and 1 inappropriate (table 3 ). The final three best practice statements from the 'reassessment and completion' module were developed once the 'initial assessment' module had been finalised through the Delphi process. This was to ensure the final two statements were appropriate and mirrored statements from the first module. While these statements did not go through the Delphi process, they were approved by the EAG via email correspondence.

\section{Final organisational review}

The programme content underwent a final review process with the National Heart Foundation to ensure concordance with the organisation's secondary prevention recommendations and clinical guidelines. After review from the Heart Foundation Clinical Committee, minor adjustments were made to wording, assessment priorities and selected screening tools. The only best practice statement that required consideration was the assessment of sleep (initial assessment module, desirable rating)—due to low levels of evidence it was decided by the organisation that this should be removed. No other changes to the overarching best practice statements were required, thus maintaining the rigorous programme outline development methodology.

\section{DISCUSSION}

The development of standardised programme content for phase II CR in Australia was achieved using the RAM method, which involved a comprehensive literature review, expert consensus and end user consultation. Specifically, 29 essential and 18 desirable best practice statements across four module categories were developed and validated. While these best practice statements largely align with international guidelines, we have produced a programme that uniquely focuses on comprehensive care-extending psychosocial wellbeing beyond anxiety and depression to acknowledge the role that social support can play in recovery. Furthermore, the 'activities of daily living' module was particularly guided by consumers to ensure the resource provides practical guidance around activities such as driving, sexual intercourse and learning cardiopulmonary resuscitation skills.

Variation in the quality of secondary prevention care is an issue globally. Optimal preventative care (ie, prescription of preventative medications, lifestyle advice and referral to CR) is estimated to occur in only $25 \%$ of the Australian cardiac population. ${ }^{50}$ In the UK, the delivery of CR varies widely. Using data from the National Audit of Cardiac Rehabilitation, only $30 \%$ of CR sites achieved criteria for high performance; $18 \%$ of sites were reported as having low performance; and a further $5 \%$ failed to meet any criteria. ${ }^{51}$ Such variation in quality is concerning as it highlights that many patients do not receive optimal care, which may impact on their experience and outcomes. This Australian standardised programme of content has considerable potential to guide CR programmes across the country, by ensuring critical features of CR are included. In addition, with recent work by the International Council of Cardiovascular Prevention and Rehabilitation demonstrating significant regional variation of programme globally, this work will potentially assist other countries or regions who similarly lack standardisation and CR guidelines. ${ }^{52}$

The RAM process enabled the combination of best current evidence with expert consensus and end user participation. This approach has been used in the development of statements in pharmacy ${ }^{53}$ and aphasia care. ${ }^{54}$ The benefit of this approach is that it enables consensus-based recommendations in the absence of national guidelines. Priorities for quality improvement of Australian CR would be to use the research underpinning this programme content and feed it into national CR guidelines. These could be stand-alone or could be a supplement to existing ACS, ${ }^{21}$ heart failure ${ }^{55}$ and atrial fibrillation ${ }^{56}$ guidelines.

Our methods of developing this programme content also align with the Heart Foundation One Heart Strategy ${ }^{57}$ where resources are centrally coordinated and delivered with local presence and expertise. We do however acknowledge the potential inherent disparities between programmes that are due to geographical locations or programme size. With the ubiquity of the use of digital and mobile health, we believe barriers such as access to specialist services may now be more easily overcome. By having standardised programme content, smaller, regional or rural services will now be able to demonstrate 
Table 3 Finalised best practice statements $(n=45)$

\begin{tabular}{|c|c|c|c|}
\hline Number & Best Practice Statement & $\begin{array}{l}\text { RAM Round two } \\
\text { median score } / 9\end{array}$ & Essential or desirable \\
\hline \multicolumn{4}{|c|}{ Initial assessment module } \\
\hline 1.2 & The initial assessment should include clinical history & 9 & Essential \\
\hline 1.3 & The initial assessment should include exercise capacity & 9 & Essential \\
\hline 1.5 & $\begin{array}{l}\text { The initial assessment should include medical risk factors (blood } \\
\text { pressure, lipids, blood glucose) }\end{array}$ & 9 & Desirable \\
\hline 1.6 & $\begin{array}{l}\text { The initial assessment should include lifestyle risk factors } \\
\text { (physical activity, diet, smoking, alcohol) }\end{array}$ & 9 & Essential $\wedge$ \\
\hline 1.9 & The initial assessment should include medications & 9 & Essential^ \\
\hline 1.10 & $\begin{array}{l}\text { The initial assessment should include return to activities of daily } \\
\text { living }\end{array}$ & 8 & Desirable \\
\hline 1.11 & $\begin{array}{l}\text { Following the initial assessment, CR participants should be } \\
\text { encouraged to set achievable goals with support from CR staff. }\end{array}$ & 9 & Essential \\
\hline
\end{tabular}

\section{Heart education and self-management module}

2.1 CR participants should be provided with education, tailored where $8.5 \quad$ Desirable possible to their condition about anatomy and physiology of the heart; return to activities, risk factors, chest pain management or heart failure management plan.

$\begin{array}{llll}\text { CR participants should be provided with education on self- } & 8.5 & \text { Essential } \\ \text { management strategies } & \end{array}$

\section{Medication education and review module}

$\begin{array}{llcl}\text { 3.1 } & \begin{array}{l}\text { CR participants should be provided with medication education } \\ \text { that includes basic indications and benefits of commonly } \\ \text { prescribed medication therapy. }\end{array} & \text { Essential } \\ \text { 3.2 } & \begin{array}{l}\text { CR participants should be encouraged and supported to adopt } \\ \text { strategies that lead to medication adherence. }\end{array} & 9 & \text { Essential } \\ \text { 3.3 } & \begin{array}{l}\text { CR staff (pharmacist where possible) should review CR } \\ \text { participants medications to ensure optimisation of cardio- } \\ \text { protective medications. }\end{array} & 7.5 & \text { Desirable }\end{array}$

\section{Managing medical risk factors module}

$\begin{array}{llll}4.1 & \begin{array}{l}\text { CR programmes should provide education and skills for } \\ \text { participants to self-manage or prevent hypertension }\end{array} & 8 & \text { Essential^ } \\ 4.2 & \begin{array}{l}\text { CR programmes should provide education and skills for } \\ \text { participants to self-manage or prevent dyslipidaemia }\end{array} & 8 & \text { Essential^ } \\ \text { CR programmes should provide education and skills for } & 8 & \text { Essential } \\ \text { participants to self-manage or prevent diabetes }\end{array}$

\section{Exercise training and physical activity module}

\begin{tabular}{llcl}
\hline 5.1 & $\begin{array}{l}\text { CR participants should be provided with a tailored, progressive } \\
\text { and supervised exercise training programme. }\end{array}$ & Essential \\
5.2 & $\begin{array}{l}\text { CR participants are provided with education and strategies to } \\
\text { increase general physical activity and reduce sedentary behaviour. }\end{array}$ & Essential \\
\hline $\begin{array}{l}\text { Healthy eating \& weight management module } \\
\text { The focus of advice should be on making healthy dietary choices }\end{array}$ & 9 & Essential \\
& to reduce total cardiovascular risk.
\end{tabular}


Table 3 Continued

\section{Number Best Practice Statement}

RAM Round two

median score $/ 9$

6.2 If resources allow, offer individualised consultation with a trained health professional to discuss diet including understanding the CR participant's current eating habits and provide personalised advice that is sensitive to culture, needs, socio-economic status, and capabilities.

6.3 Patients with additional co-morbidities leading to more complex

8

Desirable dietary requirements should be assessed and managed by an Accredited Practising Dietitian.

6.4 Education and advice should be provided on the importance of maintaining a healthy weight for heart health. For CR participants who are overweight or obese, develop an individualised, achievable plan working towards an initial goal of losing $10 \%$ of body weight and a longer-term goal of achieving a body mass index below 25 .

Referral to weight-loss programmemes delivered by experts 7 should be considered for patients requiring assistance with weight management.

\section{Tobacco cessation and alcohol reduction module}

\begin{tabular}{|c|c|c|c|}
\hline 7.1 & $\begin{array}{l}\text { A brief intervention for smoking cessation by a CR clinician should } \\
\text { be provided to CR participants who smoke using the Ask, Advice } \\
\text { and Help model. }\end{array}$ & & Essential \\
\hline 7.2 & $\begin{array}{l}\text { CR participants should be encouraged to use a combination } \\
\text { of nicotine replacement products (patch plus gum or spray or } \\
\text { lozenge or inhalator) or "stop smoking medications" (varenicline, } \\
\text { bupropion) to assist quitting. }\end{array}$ & 9 & Essential \\
\hline 7.3 & $\begin{array}{l}\text { CR participants who are excessive drinkers should be offered } \\
\text { brief advice/counselling to encourage reduction of alcohol intake. }\end{array}$ & 8.5 & Essential \\
\hline 7.4 & $\begin{array}{l}\text { Consider referring CR participants who are alcohol dependent to } \\
\text { specialised services and notify their general practitioner }\end{array}$ & 8 & Desirable \\
\hline
\end{tabular}

\section{Psychosocial well-being module}

\begin{tabular}{|c|c|c|c|}
\hline 8.1 & $\begin{array}{l}\text { CR participants should be screened for depression and anxiety } \\
\text { at the beginning and end of the CR programme using a validated } \\
\text { tool. }\end{array}$ & 9 & Essential \\
\hline 8.2 & $\begin{array}{l}\text { An assessment of the social support available to the CR } \\
\text { participant is recommended and should aim to determine the } \\
\text { social support needs of the CR participant }\end{array}$ & 7 & Desirable \\
\hline 8.3 & $\begin{array}{l}\text { CR programmes should provide participants with an opportunity } \\
\text { to discuss the typical emotional response to a heart event. }\end{array}$ & 8 & Essential \\
\hline 8.4 & $\begin{array}{l}\text { CR programmes should provide education around the signs and } \\
\text { symptoms of depression and other mood disorders }\end{array}$ & 8 & Essential \\
\hline 8.5 & $\begin{array}{l}\text { CR programmes should assist CR participants to respond } \\
\text { appropriately to ongoing psychological symptoms including when } \\
\text { to seek help }\end{array}$ & 8.5 & Essential \\
\hline 8.6 & $\begin{array}{l}\text { CR programmes should discuss the importance of social support } \\
\text { on heart health recovery and encourage participants to reflect on } \\
\text { how they can enhance or better use their social support networks }\end{array}$ & 7.5 & Desirable \\
\hline 8.7 & $\begin{array}{l}\text { CR programmes should consider how social networks can be } \\
\text { enhanced for their participants who have low levels of perceived } \\
\text { social support }\end{array}$ & 6 & Desirable \\
\hline 8.8 & $\begin{array}{l}\text { Cardiac rehabilitation programmes should consider the } \\
\text { contributions family members and carers can make to a } \\
\text { participants' recovery. }\end{array}$ & 8 & Desirable \\
\hline
\end{tabular}


Table 3 Continued

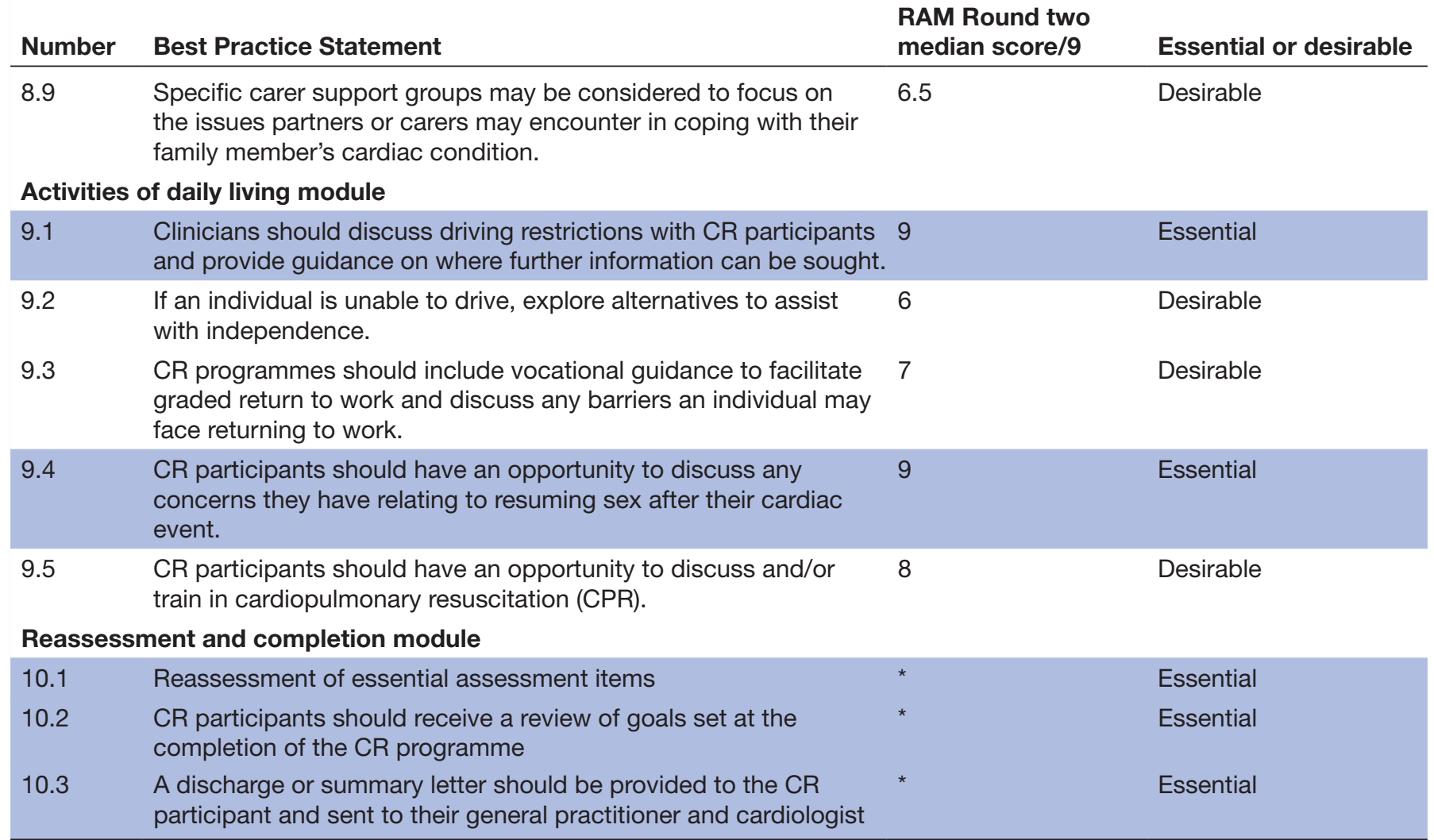

*These statements were increased to an essential rating.

†These statements did not undergo the Delphi process but were approved by the expert advisory group.

CPR, cardiopulmonary resuscitation; CR, cardiac rehabilitation.

the need for care delivery and resources to align with best practice statements that are defined as essential. In addition, the programme content was written with the goal of being delivery agnostic, therefore being suitable for delivery via digital health programme that are already beginning to emerge. ${ }^{58}$

Programme standardisation eliminates unnecessary work for clinicians to determine what content their programme should be delivering. This was voiced by local CR coordinators during the end user forum, who wished to see more guidance provided for an Australian CR context. Standardisation allows clinicians more time to spend with participants, and to tailor and individualise the care within the standard programme content. Further, the resource provides direct guidance on what content to implement, with useful resources, links and examples on how essential aspects of a CR programme can be delivered. Given the implementation science literature has consistently reported on a failure to translate evidence into practice ${ }^{59}$ it is crucial that research and clinical knowledge are synthesised and translated into usable tools for clinicians to ensure patients can benefit from optimal healthcare.

Increasingly, funders, providers and consumers of healthcare are invested and focused on care quality. The CR model in the UK has multiple components at the health system level working towards care reform of secondary prevention services including: minimum standards (as defined by the British Association for Cardiovascular Prevention and Rehabilitation), clinical guidance (provided by the National Institute for Health and Care Excellence) and a National Certification Programme for CR. ${ }^{51}$ Currently in Australia, there is recognition of the importance of quality in CR, as several states are in the process, or have developed, quality indicators. ${ }^{45-49}$ There is now work underway to create national quality indicators. ${ }^{60}$ However, Australian CR has many steps to realise standardisation and auditing of care quality of CR at state or national levels. In addition the development of state-based registries and national quality indicators also needs to be actioned. ${ }^{45}$ Standardisation paired with data can then measure the quality of care provided, allow for other processes such as benchmarking and provide further specific data to guide treatment plans for patient sub-groups.

\section{Strengths and limitations}

The strengths of our programme content for Australian CR programmes include using an extensive literature search, paired with a robust method to validate best practice statements using national experts. We also followed RAM method closely by ensuring members of the team 
had conducted the RAM process before as the manual strongly advocates the process of 'seeing one' before 'doing one'. ${ }^{,}$

There are however some limitations of this methodology where the participants of the RAM process may not be able to extend their vision to the wider context of the problem. ${ }^{61}$ We did however try and balance this with the presence of consumers within the EAG, and specifically consulted them when panel discussions could not easily be resolved. Second, the literature review was not systematic and therefore it is possible that studies, guidelines or core components may have been missed from our review. Performing a systematic review was outside of the scope of this project; however, we aimed to ensure the review followed the RAM manual, was comprehensive by searching multiple databases and checking reference lists of included studies and documents in addition to consulting with the EAG. Finally, this study was conducted in one state of Australia; however, the membership of the EAG included people from across Australia in order to give wider perspective and so that this work can be implemented on a national scale in the near future. The membership of the EAG was not representative of all clinician, researcher and consumer views; however, we aimed for broad representation in the first instance and aim to conduct additional focus testing once the resource is implemented.

\section{Future directions}

The next phase of this work is underway and includes the development of a web-based resource. The final resource will be assessed by end users to ensure it is appropriate, acceptable and easy to use for CR coordinators and staff. In addition, ideally the future online resource will be dynamic, enabling updates to occur as new evidence becomes available and defray the costs of reprinting hard copy publications. While the current resource refers readers to a companion document that outlines CR and secondary prevention for Aboriginal and Torres Strait Islander Peoples, ${ }^{62}$ in the future we would like to see this updated and integrated into the one resource.

Resources will then be rolled out to end users, initially in Victoria through the Heart Foundation, Safer Care Victoria and the ACRA state chapter. The resource should make it easy for current CR programmes to assess whether the education component of their programme meets our best practice statements, especially in terms of ensuring they meet best practice statements classed as essential. Importantly, to aid in translation, future work with end users via ACRA and Heart Foundation networks is planned (webinars, seminar, etc)

\section{Implications}

While this work has been focused in the state of Victoria, dissemination of the outlines is planned nationally. We would expect to initially see implementation at the local level, whereby coordinators ensure their programme includes the essential best practice statements. It is anticipated that this would be the starting point towards national standardisation, which aligns closely with the current work being undertaken with CR quality indicators in Australia. ${ }^{60}$ The process of developing this standardised programme content has been invaluable for reinforcing critical links within the Australian CR landscape (Heart Foundation, government, ACRA). This work has also assisted with driving the momentum of CR advancement in Australia to aid with increasing consistency and quality. This is important not only for the traditional face-to-face programme, but for new and emerging methods of CR delivery such as mobile health. The next logical step is to then investigate the best way for this content to be delivered, so guidance can also be developed for the optimum delivery of this content.

\section{CONCLUSION}

We have developed an evidence-based, expert consensusdriven standardised programme content for CR in Australia comprising of 47 best practice statements within ten modules. In light of the absence of Australian CR clinical guidelines, this programme outline provides an essential resource for CR programme coordinators and staff.

\section{Twitter Susie Cartledge @susiecartledge}

Acknowledgements We wish to acknowledge the expert advisory group for their input and guidance in the development of this project. We also thank the cardiac rehabilitation consumers and ACRA Victoria members who reviewed the modules and provided valuable feedback on their utility within the clinical setting. Additional expert advice was also sought from Sarah White (Quit Victoria) and Cia Connell (Heart Foundation). We would also like to acknowledge Eugene Lugg (Heart Foundation) for ongoing assistance with translation of this work.

Contributors SC, ET, KH and RM contributed to the project conceptualisation, design and editing of the final manuscript. SC and ET undertook data collection and analysis. SC, ET and RM drafted the manuscript. All authors have contributed to the critical editing of the paper. All authors take responsibility for the accuracy and integrity of the data, and have given approval for the final version to be published.

Funding This work was supported by Safer Care Victoria.

Competing interests SC received financial support from a Deakin University Dean's Postdoctoral Research Fellowship. SC has also undertaken shortterm consultancy for Medibank Private, not directly related to this work. ET received financial support from a National Health and Medical Research Council postgraduate scholarship (1113920).

Patient consent for publication Not required.

Ethics approval Ethics approval for participation in the Delphi process and the public forum was obtained from the Deakin University Human Ethics Advisory Group, Faculty of Health (HEAG-H 144_2018).

Provenance and peer review Not commissioned; externally peer reviewed.

Data availability statement Data are available upon reasonable request.

Open access This is an open access article distributed in accordance with the Creative Commons Attribution Non Commercial (CC BY-NC 4.0) license, which permits others to distribute, remix, adapt, build upon this work non-commercially, and license their derivative works on different terms, provided the original work is properly cited, appropriate credit is given, any changes made indicated, and the use is non-commercial. See: http://creativecommons.org/licenses/by-nc/4.0/.

ORCID iD

Susie Cartledge http://orcid.org/0000-0002-6837-2244 


\section{REFERENCES}

1 Australian Institute of Health and Welfare. Australia's welfare 2015. Canberra: AlHW, 2015. https://www.aihw.gov.au/getmedia/692fd1d40e81-41da-82af-be623a4e00ae/18960-aw15.pdf.aspx?inline=true

2 Nichols M, Peterson K, Herbert J, et al. Australian heart disease statistics 2015. Melbourne: National Heart Foundation, 2016. https:// www.heartfoundation.org.au/images/uploads/publications/RES-115Aust_heart_disease_statstics_2015_WEB.PDF

3 Australian Institute of Health and Welfare. Australia's health series. Canberra, Australia, 2014. http://www.aihw.gov.au/WorkArea/ DownloadAsset.aspx?id=60129548150

4 World Health Organization. Non-communicable diseases factsheet. Geneva, 2015. http://www.who.int/mediacentre/factsheets/fs355/en/

5 Chew DP, Amerena JV, Coverdale SG, et al. Invasive management and late clinical outcomes in contemporary Australian management of acute coronary syndromes: observations from the ACACIA registry. Med J Aust 2008;188:691-7.

6 Woodruffe S, Neubeck L, Clark RA, et al. Australian cardiovascular health and rehabilitation association (acrA) core components of cardiovascular disease secondary prevention and cardiac rehabilitation 2014. Heart Lung Circ 2015;24:430-41.

7 Anderson L, Thompson DR, Oldridge N, et al. Exercise-based cardiac rehabilitation for coronary heart disease. Cochrane Database Syst Rev 2016:CD001800.

8 World Health Organisation. Needs and action priorities in cardiac rehabilitation and secondary prevention in patients with coronary heart disease. Geneva WHO Reg Off Eur 1993:6.

9 Anderson L, Taylor RS. Cardiac rehabilitation for people with heart disease: an overview of Cochrane systematic reviews. In: Cochrane database of systematic reviews. John Wiley \& Sons, Ltd, 2014.

10 Jelinek MV, Thompson DR, Ski C, et al. 40 years of cardiac rehabilitation and secondary prevention in post-cardiac ischaemic patients. are we still in the wilderness? Int J Cardiol 2015;179:153-9.

11 Jackson AC, Higgins RO, Murphy BM, et al. Cardiac rehabilitation in Australia: a brief survey of program characteristics. Heart Lung Circ 2018;27:1415-20.

12 Jackson AC, Le Grande MR, Higgins RO, et al. Psychosocial screening and assessment practice within cardiac rehabilitation: a survey of cardiac rehabilitation coordinators in Australia. Heart Lung Circ 2017;26:64-72.

13 Abell B, Glasziou P, Briffa T, et al. Exercise training characteristics in cardiac rehabilitation programmes: a cross-sectional survey of Australian practice. Open Heart 2016;3.

14 National Heart Foundation of Australia, Australian Cardiac Rehabilitation Association. Recommended framework for cardiac rehabilitation, 2004.

15 National Heart Foundation of Australia. Reducing risk in heart disease. An expert guide to clinical practice for secondary prevention of coronary heart disease, 2012. Available: https://www. heartfoundation.org.au/images/uploads/publications/Reducing-riskin-heart-disease.pdf

16 Briffa T, Chow CK, Clark AM, et al. Improving outcomes after acute coronary syndrome with rehabilitation and secondary prevention. Clin Ther 2013;35:1076-81.

17 Fitch K, Bernstein SJ, Aguilar MD, et al. The RAND/UCLA appropriateness method user's manual, 2001.

18 National Health and Medical Research Council. NHMRC additional levels of evidence and grades for recommendations for developers of guidelines, 2009. Available: https://www.mja.com.au/sites/default/ files/NHMRC.levels.of.evidence.2008-09.pdf [Accessed 21 Feb 2018].

19 McGory ML, Kao KK, Shekelle PG, et al. Developing quality indicators for elderly surgical patients. Ann Surg 2009;250:338-47.

20 Kravitz RL, Park RE, Kahan JP. Measuring the clinical consistency of panelists' appropriateness ratings: the case of coronary artery bypass surgery. Health Policy 1997;42:135-43.

21 Chew DP, Scott IA, Cullen L, et al. National Heart Foundation of Australia \& Cardiac Society of Australia and New Zealand: Australian Clinical Guidelines for the Management of Acute Coronary Syndromes 2016. Heart Lung Circ 2016;25:895-951.

22 New Zealand Guidelines Group. Best practice evidence-based guideline cardiac rehabilitation, 2002.

23 Scottish Intercollegiate Guidelines Network. Cardiac rehabilitation, a national clinical guideline, 2017. Available: https://www.sign.ac.uk/ assets/sign150.pdf [Accessed 1 Feb 2018]

24 National Institute for Health and Care Excellence (NICE). Myocardial infarction: cardiac rehabilitation and prevention of further cardiovascular disease, 2013. Available: https://www.nice.org. uk/guidance/cg172/evidence/myocardial-infarction-secondaryprevention-full-guideline-248682925 [Accessed 1 Feb 2018].
25 The British Association for Cardiovascular Prevention and Rehabilitation. The BACPR standards and core components for cardiovascular disease prevention and rehabilitation 2012. 2nd edn, 2012. http://www.bacpr.com/resources/46C BACPR Standards and_Core_Components_2012.pdf

26 Hamm LF, Sanderson BK, Ades PA, et al. Core competencies for cardiac rehabilitation/secondary prevention professionals: 2010 update: position statement of the American association of cardiovascular and pulmonary rehabilitation. J Cardiopulm Rehabil Prev 2011;31:2-10.

27 Achttien RJ, Staal JB, van der Voort S, et al. Exercise-based cardiac rehabilitation in patients with coronary heart disease: a practice guideline. Neth Heart J 2013;21:429-38.

28 Canadian Association of Cardiovascular Prevention and Rehabilitation. Canadian guidelines for cardiac rehabilitation and cardiovascular disease prevention: translating knowledge into action. 3rd edn, 2009. https://cacpr.ca/Guidelines

29 Piepoli MF, Hoes AW, Agewall S, et al. 2016 European Guidelines on cardiovascular disease prevention in clinical practice: The Sixth Joint Task Force of the European Society of Cardiology and Other Societies on Cardiovascular Disease Prevention in Clinical Practice (constituted by representatives of 10 societies and by invited experts) Developed with the special contribution of the European Association for Cardiovascular Prevention \& Rehabilitation (EACPR). Eur Heart $J$ 2016;37:2315-81.

30 World Health Organisation. Prevention of cardiovascular disease : guidelines for assessment and management of total cardiovascular risk, 2007. Available: https://apps.who.int/iris/handle/10665/43685 [Accessed 12 Feb 2019].

31 Leon AS, Franklin BA, Costa F, et al. Cardiac rehabilitation and secondary prevention of coronary heart disease. Circulation 2005;111:369-76.

32 Piepoli MF, Corrà U, Adamopoulos S, et al. Secondary prevention in the clinical management of patients with cardiovascular diseases. Core components, standards and outcome measures for referral and delivery: a policy statement from the cardiac rehabilitation section of the European Association for Cardiovascular Prevention \& Rehabilitation. Endorsed by the Committee for Practice Guidelines of the European Society of Cardiology. Eur J Prev Cardiol 2014;21:664-81.

33 British Association for Cardiovascular Prevention and Rehabilitation. The BACPR standards and core components for cardiovascular disease prevention and rehabilitation 2017. 3rd edn, 2017. http:// www.bacpr.com/resources/BACPR_Standards_and_Core Components_2017.pdf

34 Taylor RS, Sagar VA, Davies EJ, et al. Exercise-based rehabilitation for heart failure. Cochrane Database Syst Rev 2014;7.

35 Karmali KN, Davies P, Taylor F. Promoting patient uptake and adherence in cardiac rehabilitation. In: Cochrane database of systematic reviews. John Wiley \& Sons, Ltd, 2014.

36 Devi R, Singh SJ, Powell J, et al. Internet-Based interventions for the secondary prevention of coronary heart disease. Cochrane Database Syst Rev 2015:CD009386.

37 Anderson L, Oldridge N, Thompson DR, et al. Exercise-based cardiac rehabilitation for coronary heart disease: cochrane systematic review and meta-analysis. J Am Coll Cardiol 2016;67:1-12.

38 Byrne M, Doherty S, Fridlund BGA, et al. Sexual counselling for sexual problems in patients with cardiovascular disease. Cochrane Database Syst Rev 2016;2.

39 Sibilitz KL, Berg SK, Tang LH, et al. Exercise-based cardiac rehabilitation for adults after heart valve surgery. Cochrane Database Syst Rev 2016;3.

40 Risom SS, Zwisler A-D, Johansen PP, et al. Exercise-based cardiac rehabilitation for adults with atrial fibrillation. Cochrane Database Syst Rev 2017;2.

41 Anderson L, Nguyen TT, Dall CH, et al. Exercise-based cardiac rehabilitation in heart transplant recipients. Cochrane Database Syst Rev 2017;4

42 Richards SH, Anderson L, Jenkinson CE, et al. Psychological interventions for coronary heart disease. Cochrane Database Syst Rev 2017;67.

43 Anderson L, Brown JPR, Clark AM, et al. Patient education in the management of coronary heart disease. Cochrane Database Syst Rev 2017;314.

44 Anderson L, Sharp GA, Norton RJ, et al. Home-Based versus centrebased cardiac rehabilitation. Cochrane Database Syst Rev 2017;6.

45 Zecchin R, Candelaria D, Ferry C, et al. Development of quality indicators for cardiac rehabilitation in Australia: a modified Delphi method and pilot test. Heart Lung Circ 2019;28.

46 Queensland Health. Statewide cardiac clinical network Queensland cardiac outcomes registry: 2017 annual report, 2018. Available: 
https://clinicalexcellence.qld.gov.au/priority-areas/clinicianengagement/statewide-clinical-networks/

47 Tavella R, O'Toole K, Tirimacco R, et al. Cardiac rehabilitation referral and completion: results from the South Australian minimum dataset for cardiac rehabilitation programs. Heart Lung Circ 2015;24:S451-2.

48 Thomas E, Grace S, Boyle D, et al. Feasibility of utilising an electronic data Scraping tool to develop a cardiac rehabilitation registry. Heart Lung Circ 2018;27.

49 National Heart Foundation of Australia. Improving the delivery of cardiac rehabiliation in Australia: The Heart Foundation's Cardiac Rehabilitation Advocacy Strategy, 2014. Available: https://www. heartfoundation.org.au/images/uploads/publications/Improving-thedelivery-of-cardiac-rehabilitation.pdf

50 Redfern J, Hyun K, Chew DP, et al. Prescription of secondary prevention medications, lifestyle advice, and referral to rehabilitation among acute coronary syndrome inpatients: results from a large prospective audit in Australia and New Zealand. Heart 2014;100:1281-8.

51 Doherty P, Salman A, Furze G, et al. Does cardiac rehabilitation meet minimum standards: an observational study using UK national audit? Open Heart 2017;4:e000519.

52 Supervia M, Turk-Adawi K, Lopez-Jimenez F, et al. Nature of cardiac rehabilitation around the globe. EClinicalMedicine 2019;13:46-56.

53 Basger BJ, Chen TF, Moles RJ. Validation of prescribing appropriateness criteria for older Australians using the RAND/UCLA appropriateness method. BMJ Open 2012;2:e001431.

54 Power E, Thomas E, Worrall L, et al. Development and validation of Australian aphasia rehabilitation best practice statements using the RAND/UCLA appropriateness method. BMJ Open 2015;5:e007641.
55 Atherton JJ, Sindone A, De Pasquale CG, et al. National heart Foundation of Australia and cardiac Society of Australia and New Zealand: guidelines for the prevention, detection, and management of heart failure in Australia 2018. Heart Lung Circ 2018;27:1123-208.

56 Brieger D, Amerena J, Attia J, et al. National heart Foundation of Australia and the cardiac Society of Australia and New Zealand: Australian clinical guidelines for the diagnosis and management of atrial fibrillation 2018. Heart Lung Circ 2018;27:1209-66.

57 National Heart Foundation Australia. One Heart. Our 2018 - 2020 Strategy, 2017. Available: https://www.heartfoundation.org.au/ images/uploads/publications/One_Heart_2018_-_2020_Strategy.pdf

58 Gandhi S, Chen S, Hong L, et al. Effect of mobile health interventions on the secondary prevention of cardiovascular disease: systematic review and meta-analysis. Can J Cardiol 2017;33:219-31.

59 Grimshaw JM, Eccles MP, Lavis JN, et al. Knowledge translation of research findings. Implement Sci 2012;7.

60 South Australian Academic Health Science and Translation Centre. Improving cardiac rehabilitation measurement in Australia think tank Communique. South Australia, Australia: South Australian Academic Health Science and Translation Centre, 2018. https://www. heartfoundation.org.au/images/uploads/main/241018_Communique_ FINAL.pdf

61 Vernon W. The Delphi technique: a review. Int J Ther Rehabil 2009;16:69-76.

62 Australian Government, National Health and Medical Research Council. Strengthening cardiac rehabilitation and secondary prevention for Aboriginal and Torres Strait Islander peoples. A guide for health professionals., 2005. Available: https://daa.asn.au/ wp-content/uploads/2016/07/MR_Cultural_Competency_Toolkit_ NHMRC_2005.pdf 